\title{
Direct enzymatic esterification of cotton and Avicel with wild-type and engineered cutinases
}

\author{
Teresa Matamá · Margarida Casal • \\ Artur Cavaco-Paulo
}

\begin{abstract}
In this work, the surface of cellulose, either Avicel or cotton fabric, was modified using cutinases without any previous treatment to swell or to solubilise the polymer. Aiming further improvement of cutinase ester synthase activity on cellulose, an engineered cutinase was investigated. Wild-type cutinase from Fusarium solani and its fusion with the carbohydratebinding module N1 from Cellulomonas fimi were able to esterify the hydroxyl groups of cellulose with distinct efficiencies depending on the acid substrate/ solvent system used, as shown by titration and by ATRFTIR. The carbonyl stretching peak area increased significantly after enzymatic treatment during $72 \mathrm{~h}$ at $30{ }^{\circ} \mathrm{C}$. Cutinase treatment resulted in relative increases of 31 and $9 \%$ when octanoic acid and vegetable oil were used as substrates, respectively. Cutinase-N1 treatment resulted in relative increases of 11 and $29 \%$ in the peak area when octanoic acid and vegetable oil were used as substrates, respectively. The production
\end{abstract}

T. Matamá - M. Casal

CBMA, Centre of Molecular and Environmental Biology, Department of Biology, University of Minho, Campus Gualtar, 4710-057 Braga, Portugal

T. Matamá

Textile Engineering Department, University of Minho, Campus Azurém, 4800-058 Guimarães, Portugal

A. Cavaco-Paulo ( $\square)$

Department of Biological Engineering, University of Minho, Campus Gualtar, 4710-057 Braga, Portugal e-mail: artur@deb.uminho.pt and application of cutinase fused with the domain N1 as a cellulose ester synthase, here reported for the first time, is therefore an interesting strategy to pursuit.

Keywords Cellulose ester - Reverse esterase . Transesterification - Carbohydrate-binding module . Caprylic acid

\section{Introduction}

Cellulose is the most abundant natural polymer and it is a valuable natural resource (Steinmann 1998). The more traditional industrial applications of cellulose are paper and textiles but the development on cellulose chemistry allowed new processes and a continuous growth of its derivatives. As the expected consequence of cellulose molecular structure, esterification is a well explored route to modify either homogeneous or heterogeneously this polysaccharide. Several approaches aiming at cellulose esterification are described in the literature (Vaca-Garcia et al. 1998; Freire et al. 2006; Braun and Dorgan 2009; Uschanov et al. 2011). The low molecular weight cellulose esters have been used as a raw material for plastics, textiles, filter tows, films or membranes (Edgar et al. 2001; Rustemeyer 2004). More recently, a growing interest in cellulose nanostructures has boost research on surface esterification of cellulose with long fatty acids in order to overcome its incompatibility with nonpolar matrices while preserving the desired mechanical properties (Braun and Dorgan 2009; Uschanov et al. 2011). 
In a textile context, cellulose esterification is the basis of durable chemical finishing methods. Through textile finishing, the surface of fibres can be modified to add useful qualities to the fabric, ranging from attractive appearance and fashion aspects to high performance properties for particular industrial needs (Schindler and Hauser 2004). Almost all apparel and home furnishing textiles are treated with softeners because, during their processing, natural oils and waxes are often removed (Schindler and Hauser 2004). Another important cotton treatment based on esterification is the durable press finish. There are recent publications concerned with the easy-care properties improvement of cotton by ester crosslinking of cellulose without resorting to formaldehyde-releasing compounds (Ford et al. 2011; Hashem et al. 2011; Fouda and Fahmy 2011; Peng et al. 2012).

The chemical surface modification of textile polymers, in addition to the environmental issues, is not always easy to control and in some cases severe fibre yellowing and weight lost occur (Gübitz and CavacoPaulo 2008). Enzymes are a good alternative to chemical surface modification due to several reasons. As macromolecules, they are well-suited for targeting surface functionalization of polymers since their mode of action is normally restricted to the most superficial layers of polymer fibres. They are considered green catalysts not just because they are biodegradable themselves but also because of their mild operating conditions (Rozzell 1999). Besides, many enzymes can accept unnatural substrates. The specificity, the stability and the specific activity can be further improved through genetic modifications, and reaction medium engineering can modulate their catalytic properties (Koeller and Wong 2001).

In this work we present a new approach for the simple and direct biomodification of hydroxyl groups on the surface of cellulose, either as Avicel or as plain woven cotton fabric, a heterogeneous reaction where the players are not all in the same physical state. Using a well known cutinase, from Fusarium solani pisi (Araújo et al. 2007; Purdy and Kolattukudy 1975a, b) and a chimeric cutinase fused with the carbohydratebinding module (CBM) N1 of the Endoglucanase C (CenC) from Cellulomonas fimi (Matamá et al. 2010), the accessible hydroxyl groups of cellulose were esterified with octanoic acid in isooctane and with edible vegetable oil. Cutinase is a very versatile enzyme: it can use a broad range of substrates, it is rather stable and at low water activities cutinase catalyses the reverse reaction-transesterification of fats and selective esterification of alcohols (Badenes et al. 2010; de Barros et al. 2009, 2010, 2011). Very recently, a commercial immobilized cutinase from $F$. solani has been used to acylate cellulose with long fatty acids in non conventional media with the ultimate purpose of conferring a thermoplastic behaviour to the polymer (Gremos et al. 2011a, b). In water, the fusion of cutinase with $\mathrm{N} 1$ domain of CenC resulted in an increase of esterase activity yield on cellulose acetates when compared to the wild-type cutinase (Matamá et al. 2010). A major outcome of the present study was the insight that the fusion with $\mathrm{CBM}$ $\mathrm{N} 1$ also presents particular advantages in organic media to the reverse esterase activity of cutinase on cellulosic substrates.

\section{Experimental}

Reagents and enzymes

The properties of the cotton fabric used in this work were: 50/66 ends/picks per $\mathrm{cm}$ and $131 \mathrm{~g} \mathrm{~m}^{-2}$. The microcrystalline cellulose powder Avicel PH-101 was purchased from Sigma-Aldrich (Sigma-Aldrich Quimica SA, Madrid, Spain). The free fatty acid used to esterify cellulose was octanoic acid (purity $\geq 98 \%$ ) from Sigma. The brand of a commercial edible-grade vegetable oil used in this work was Fula Alimentar (Sovena Group, Algés, Portugal). All other reagents were laboratory grade reagents from Sigma-Aldrich.

Expression and purification of recombinant cutinases

The DNA coding for $F$. solani pisi cutinase (EC 3.1.1.74) and for cutinase fused in frame with the carbohydrate binding module N1 (cutinase-N1) from C. fimi CenC, were cloned, and the respective proteins expressed and purified as previously reported by Matamá et al. (2010). Briefly, clones of Escherichia coli strain BL21(DE3), harbouring the constructs pCWT and pCWT::CBM $\mathrm{N}_{\mathrm{N} 1}$, were grown overnight, at $30{ }^{\circ} \mathrm{C}$ and $200 \mathrm{rpm}$, in $1 \mathrm{~L}$ of culture medium supplemented with $100 \mu \mathrm{g} \mathrm{mL}^{-1}$ ampicillin and $0.2 \% \alpha$-lactose. The cells were harvested by centrifugation and frozen at $-80{ }^{\circ} \mathrm{C}$. The ultrasonic 
disruption of the bacterial cells was accomplished on ice with a $25.4 \mathrm{~mm}$ probe in an Ultrasonic Processor VCX-400 watt (Cole-Parmer Instrument Company, Illinois, USA). The lysate was centrifuged for $30 \mathrm{~min}$ at $30,000 \mathrm{~g}$ and $4{ }^{\circ} \mathrm{C}$. The supernatant was collected and cutinase purification was done by affinity chromatography using HiTrap Chelating HP system (GE Healthcare Bio-Sciences Europe GmbH, Munich, Germany) coupled to a peristaltic pump. The cutinase-N1 was purified using its selective adsorption to Avicel PH-101 (Coutinho et al. 1992). The fractions obtained were monitored by SDS-PAGE with silver staining. The fractions of interest were frozen at $-80{ }^{\circ} \mathrm{C}$ and lyophilised (Christ Alpha 2-4 freeze dryer, B. Braun Biotech International, Melsungen, Germany).

Quantification of total protein concentration

Total protein in solution was quantified following Bradford methodology (Bradford 1976). Bovine serum albumin was used as standard. All samples were measured in triplicate.

Esterase activity assay

Esterase activity was determined following the $p$ nitrophenol release at $400 \mathrm{~nm}$ during $3 \mathrm{~min}$ at $30{ }^{\circ} \mathrm{C}$ (SepctraMax 340 PC spectrophotometer, Molecular devices, Sunnyvale, CA, United States). The final reaction volume was $300 \mu \mathrm{L}$ consisting in $275 \mu \mathrm{L}$ of $50 \mathrm{mM}$ phosphate buffer $\mathrm{pH} 7,15 \mu \mathrm{L}$ of $1.5 \mathrm{mM}$ $p$-nitrophenol butyrate in ethanol ( $\varepsilon 1.84 \times 10^{4}$ $\mathrm{M}^{-1} \mathrm{~cm}^{-1}$, de Barros et al. 2010) and $10 \mu \mathrm{L}$ of lyophilised enzymes, previously rehydrated in ultrapure water. All the assays were performed at least in triplicate. One unit (U) of esterase activity was defined as one $\mu \mathrm{mol}$ of $p$-nitrophenol released per minute.

Esterification of cotton fabric and Avicel

Several experiments were carried out varying the enzyme and the acid substrate/organic solvent. For all experiments, the treatment of cellulose substrates was performed in the Rotawash MKIII (vertical agitation simulating European washing machines, from SDL International Ltd.) operating at $30{ }^{\circ} \mathrm{C}$ and $20 \mathrm{rpm}$ for 72 h. Samples (100.2 $\pm 0.1 \mathrm{mg}$ ) of Avicel PH-101 and cotton fabric were incubated either in $10 \mathrm{~mL}$ of isooctane containing $185 \mathrm{mM}$ octanoic acid or in $10 \mathrm{~mL}$ of edible vegetable oil. The maximum enzyme load was $1.4 \mathrm{mg} \mathrm{g}^{-1}$ of cellulose. As controls, the cellulose was subjected to the same treatment but without the enzymes.

After treatment, all fabric samples and Avicel cellulose were washed twice with methanol and twice with $n$-hexane (Gremos et al. 2011b). The cellulose samples were let at room temperature inside an extractor hood during $48 \mathrm{~h}$ till complete solvent evaporation.

Relative ester content determination

The esterified cellulose samples (Avicel and cotton) were saponified according to Gremos et al. (2011b). Ten millilitres of ethanol $(75 \%)$ were added to samples and the mixture was heated at $55^{\circ} \mathrm{C}$ for $30 \mathrm{~min}$. Afterwards, $6 \mathrm{~mL}$ of $0.5 \mathrm{M} \mathrm{NaOH}$ were added; the mixture was heated at $70{ }^{\circ} \mathrm{C}$ for $30 \mathrm{~min}$ more and left to settle at room temperature for 3 days. The excess $\mathrm{NaOH}$ was measured by titration with $0.5 \mathrm{M} \mathrm{HCl}$ in the presence of phenolphthalein as indicator. An excess of $1 \mathrm{~mL}$ of acid was added and the mixture was left overnight. The excess of added acid was then titrated back with $0.5 \mathrm{M} \mathrm{NaOH}$ solution.

The ester content (\%) was determined as the relative molar percentage of the ester link regarding the total hydroxyl groups present according to the following equation:

$$
\begin{aligned}
\text { Ester content }(\%)= & \left\{\left[\mathrm{V}_{\mathrm{NaOH}}(\text { sample })\right.\right. \\
& \left.-\mathrm{V}_{\mathrm{NaOH}}(\text { control })\right] * \mathrm{C}_{\mathrm{NaOH}} \\
& -\left[\mathrm{V}_{\mathrm{HCl}}(\text { sample })-\mathrm{V}_{\mathrm{HCl}}(\text { control })\right] \\
& \left.* \mathrm{C}_{\mathrm{HCl}}\right\} /\left[3 * W_{\text {sample }} / M\left(\mathrm{C}_{6} \mathrm{H}_{9} \mathrm{O}_{5}\right)\right]
\end{aligned}
$$

where $\mathrm{V}$ is the respective volume $(\mathrm{L}), \mathrm{C}$ is the respective molar concentration, $W$ is the weight of the sample ( $\mathrm{g}$ ) and $M$ is the molar mass of the anhydroglucose repeating unit of cellulose.

Fourier transform infrared spectroscopy (FTIR)

The attenuated total reflectance (ATR) technique was used to collect the infrared spectra of cotton fabric controls and samples treated during $72 \mathrm{~h}$ with cutinase and cutinase-N1. The spectra were recorded in a Jasco FT/IR-4100 type A spectrometer (Jasco Inc., Maryland, USA) with a Golden Gate ATR accessory with a 
single reflection monolithic diamond (Specac Ltd., Slough, UK). All the absorbance spectra were acquired in the range $4,000-600 \mathrm{~cm}^{-1}$ at $8 \mathrm{~cm}^{-1}$ resolution and as result of the accumulation of 64 scans. Six different measurements were performed per sample.

\section{Results and discussion}

Without previous swelling or solubilisation, cellulose bioesterification was accomplished in a heterogeneous reaction with wild-type as well as with the genetically modified cutinase from $F$. solani pisi. Wild-type (wt) cutinase and cutinase fused with the cellulose-binding domain N1 (cutinase-N1) were produced in E. coli, purified and lyophilised. After rehydration and using $p$-nitrophenol butyrate as substrate at $30{ }^{\circ} \mathrm{C}$, the esterase activities for wt cutinase and for cutinase$\mathrm{N} 1$ were 14 and $21 \mathrm{kU} \mathrm{mg}^{-1}$, respectively. The ability of these enzymes to esterify cellulose was investigated using Avicel powder and cotton fabric. One of the acid substrates used was a high purity fatty acid, octanoic acid, diluted in isooctane so that its concentration was equimolar to the concentration of the alcohol substrate (cellulose hydroxyl groups). According to the literature, when using cutinase from $F$. solani, the highest ester yields were obtained for an acid to alcohol molar ratio of one (de Barros et al. 2009, 2011). The solvent isooctane was chosen due to its good biocompatibility and to the fact of being recognized as safe in food and beverages industrial processing by FDA (de Barros et al. 2009). In addition, the good performance of cutinase in isooctane for ester synthesis/transesterification is known (Badenes et al. 2010; de Barros et al. 2009). The other acid substrate tested in this study was common edible oil, a mixture of triglycerols and free fatty acids used without any dilution. Based on other enzymatic treatments and acquired experience with these enzymes, the esterification reaction was allowed for $72 \mathrm{~h}$ at $30^{\circ} \mathrm{C}$, under a continuous vertical agitation.

The first evaluation of ester synthase activity was done by a simple titration after complete ester saponification (Gremos et al. 2011a, b; Sereti et al. 2001). Figure 1 shows the ester content determined by this method using $100 \mathrm{mg}$ of cellulosic substrates. It was possible to detect a difference between enzymatic treated cellulose and control cellulose. Thought this approach may present some restrictions (Freire et al. 2005) along with a low analytical sensitivity considering the amounts used, it uncovered the ester formation for cotton treated with wt cutinase using octanoic acid as the acid substrate (Fig. 1a) and for both cotton and Avicel treated with cutinase-N1 in vegetable oil (Fig. 1b).

ATR-FTIR was performed to obtain further evidence of esterification by the two cutinases on cotton samples. Spectral data were normalized with a common baseline; no smoothing functions were used. The spectral zone of interest corresponding to the ester carbonyl stretching was further analysed $\left(1,730-1,750 \mathrm{~cm}^{-1}\right.$ ) (Braun and Dorgan 2009; Uschanov et al. 2011; Freire et al. 2005). Figure 2 shows the average individual spectra for the control and enzymatic treated cotton samples (curves A-C) using octanoic acid (Fig. 2a) and vegetable oil (Fig. 2b) as the acid substrates. In these spectra there are two main peaks $\left(1,734\right.$ and $\left.1,746 \mathrm{~cm}^{-1}\right)$. The peak position depends on several factors like acyl chain length and the position of the esterified carbon in the anhydroglucose ring. After subtracting the control spectrum, the resulting spectra for wt cutinase and cutinase-N1 treated samples, curves D and E, respectively, show two less prominent peaks. Table 1 summarises the area values obtained by peak fitting with Origin software. The esterification was verified by ATR-FTIR on cotton surface for both enzymes and for both acid substrates. There is an unambiguous increase in the area of both peaks on enzyme treated samples regarding the respective control. The difference between the two enzymes is significant at $1,746 \mathrm{~cm}^{-1}$. A closer look to the area of this peak reveals a good agreement between the spectrometric and titration results; cutinase-N1 has a better performance than wt cutinase in vegetable oil and the opposite stands true in octanoic acid. Wild-type cutinase treatment leads to a relative increase in the $1,746 \mathrm{~cm}^{-1}$ peak area of $31 \%$ when octanoic acid is used as substrate and of $9 \%$ when vegetable oil is used. The cutinase-N1 treatment leads to relative increases of 11 and $29 \%$ when octanoic acid and vegetable oil are used as substrates, respectively.

Directed mutagenesis and structure determination of the CBM N1 in complex with an oligosaccharide elucidated the interaction of this CBM with a single chain of cellulose revealing the most important residues (Kormos et al. 2000; Boraston et al. 2002). 


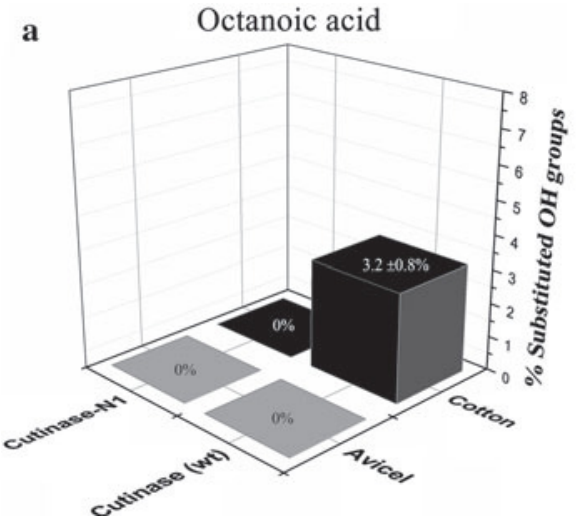

Fig. 1 Ester content (\%) calculated as the relative molar percentage of the ester link, obtained by titration after ester saponification on cellulosic samples and controls. Avicel and

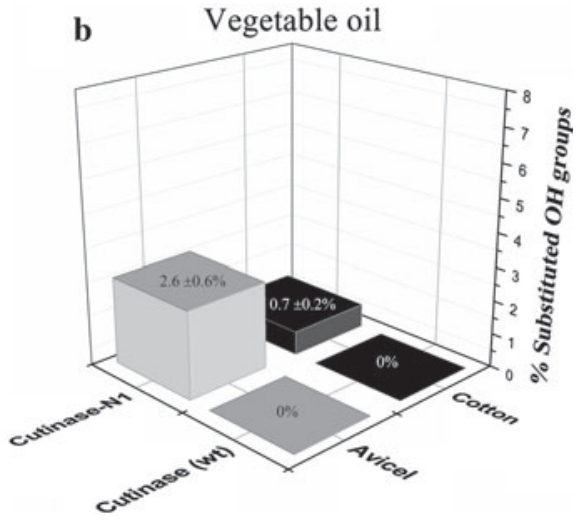

cotton were treated during $72 \mathrm{~h}$ at $30{ }^{\circ} \mathrm{C}$ with wild-type (wt) and genetically engineered (cutinase-N1) cutinases, using either octanoic acid (a) or edible vegetable oil (b) as the acid substrates
Fig. 2 Normalized ATRFTIR absorbance spectra of cotton samples and controls in the carbonyl stretching vibrations range. Cotton samples were treated during $72 \mathrm{~h}$ at $30^{\circ} \mathrm{C}$ with wild-type (wt) and genetically engineered (cutinase-N1) cutinases, using either octanoic acid (a) or edible vegetable oil (b) as the acid substrates. The curvesE and $D$ are the result of control spectra subtraction
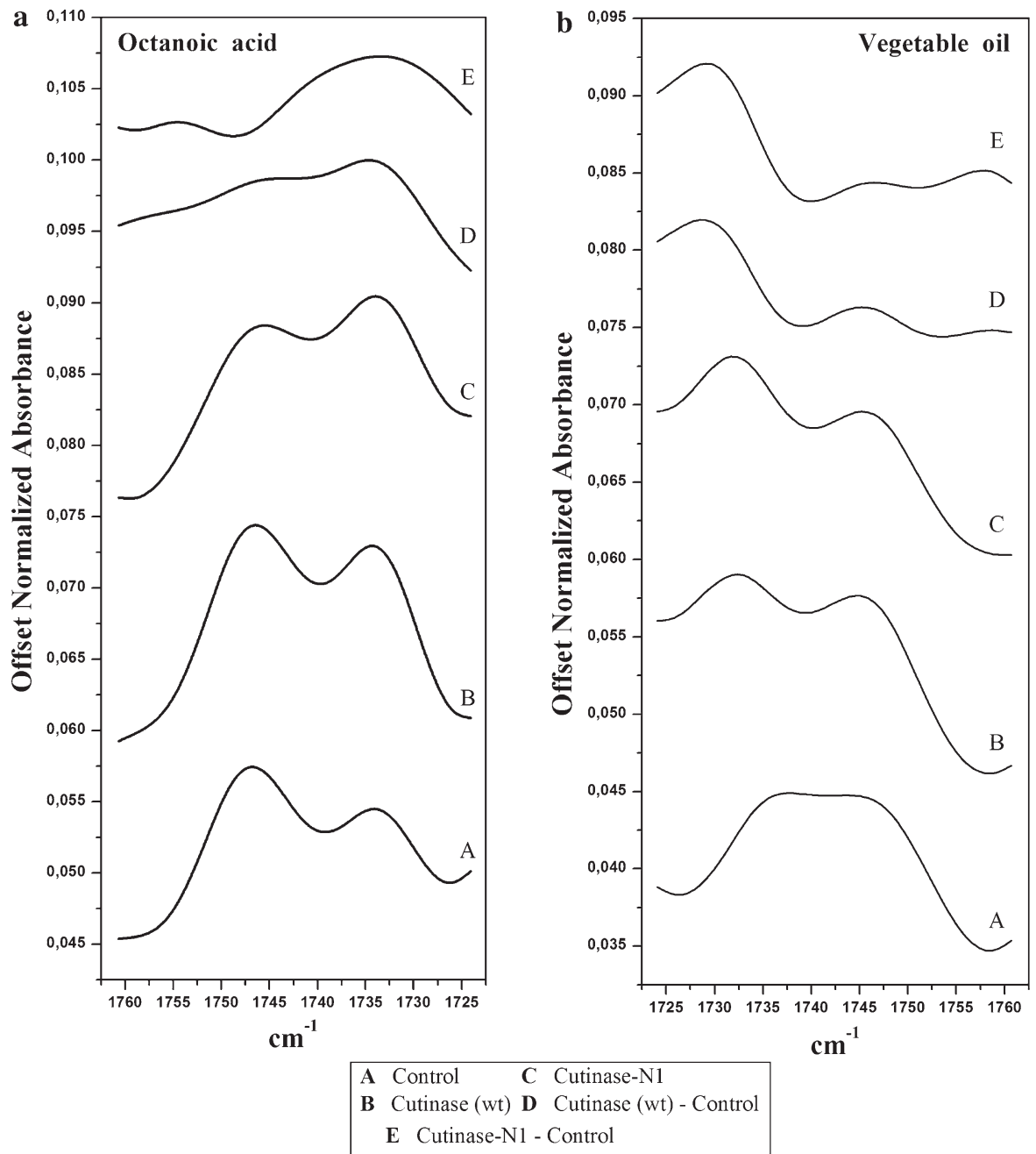
Table 1 Peak area values after Gaussian peak fitting of ATR-FTIR absorbance spectra in the range 1,724-1,760 $\mathrm{cm}^{-1}$ using Origin software

\begin{tabular}{|c|c|c|c|c|}
\hline & \multicolumn{2}{|l|}{ Octanoic acid } & \multicolumn{2}{|l|}{ Vegetable oil } \\
\hline & $1,734 \mathrm{~cm}^{-1}$ & $1,746 \mathrm{~cm}^{-1}$ & $1,734 \mathrm{~cm}^{-1}$ & $1,746 \mathrm{~cm}^{-1}$ \\
\hline Control & $0.078 \pm 0.001$ & $0.127 \pm 0.001$ & $0.056 \pm 0.002$ & $0.076 \pm 0.002$ \\
\hline Cutinase (wt) & $0.097 \pm 0.002$ & $0.167 \pm 0.003$ & $0.073 \pm 0.002$ & $0.083 \pm 0.002$ \\
\hline Cutinase-N1 & $0.101 \pm 0.002$ & $0.141 \pm 0.002$ & $0.071 \pm 0.001$ & $0.098 \pm 0.001$ \\
\hline
\end{tabular}

The side chains of polar residues form direct hydrogen bonds with the hydroxyl groups of the cellopentose and three tyrosines are involved in the interaction with the glucose rings of cellulose, mainly through van der Waals forces. The structure of CBM N1 is fairly rigid and cellulose binding is not associated with significant conformational changes. Furthermore, osmotic stress studies and the crystal structure demonstrated that the release of water from the CBM N1-ligand interface has an unusually small impact on binding (Boraston et al. 2002). Taken all together, it was reasonable to assume that the CBM N1 binding to cellulose could occur in a nonaqueous environment.

The DNA sequence and the affinity of CBM N1 from $C$. fimi were first described by Coutinho et al. (1993); it binds preferentially amorphous cellulose but it can also bind reversibly Avicel but not crystalline cellulose (Tomme et al. 1996). According to literature, the amorphous content, type of cellulose allomorphs, and crystallite size is very similar between Avicel and cotton linters (Mittal et al. 2011). The more pronounced esterification of Avicel than cotton by cutinase-N1 (Fig. 1b) could be related to surface area available for binding, but why this was verified only in vegetable oil and not in isooctane still remains unclear to the authors. Both isooctane and edible vegetable oil (soybean) are aprotic, on the other hand, viscosity and dielectric constants are different: $0.5 \mathrm{cP}\left(22^{\circ} \mathrm{C}\right)$ and $1.9\left(25{ }^{\circ} \mathrm{C}\right)$ for isooctane and $54.3 \mathrm{cP}\left(24{ }^{\circ} \mathrm{C}\right)$ and 3.1 $\left(25^{\circ} \mathrm{C}\right.$ ) for soybean oil, respectively (Noureddini et al. 1992; Lizhi et al. 2008). Different dielectric constants could explain different abilities to recognize cellulose, since solvent polarity affects the strength of noncovalent interactions either the ones involved in CBM N1 binding (Aquino et al. 2002) or in the structure stability of CBM N1, which has a relatively low maximum stability compared to other single-domain globular proteins (Creagh et al. 1998). The factor viscosity would work against the binding in vegetable oil (Sitnitsky 2010) but given the duration of the experiment and the mechanical agitation, viscosity may play a minor role.

In $F$. solani pisi cutinase, the catalytic triad is located at one edge of the ellipsoid protein, in a hydrophobic cleft rather accessible to the solvent (Prompers et al. 1999). It was verified that a cutinase from Thermobifida fusca and its null mutant possess detergency properties. A simulation study revealed that the active sites of both cutinases have great affinity to aliphatic chains and due to their amphipathic nature, the proteins improved fat stain removal from cotton samples (Silva et al. 2012). Analogously, the reason for cutinase (wt) being more efficient in octanoic acid than in vegetable oil may be the fact that the active site of cutinase is stably entrapped in oil without a cellulose-binding domain to drive the enzyme to the hydroxyl substrate.

\section{Conclusions}

Here reported, the ability to esterify the surface of cellulose in a simple, controlled and eco-friendly reaction is important not only to the textile industry but also to other areas where this key natural resource has been applied to (Freire et al. 2005, 2006; Braun and Dorgan 2009; Uschanov et al. 2011; Edgar et al. 2001). Designing engineered enzymes that mimic strategies found in Nature has become a powerful tool in synthetic biology. The idea of using cutinase-N1 was devised to mimic other carbohydrate-active enzymes which by means of CBM domains display improved activity in aqueous media The fact that cutinase and the N1 domain interact differently with their surroundings can explain the differences seen in the catalysis of cutinase (wt) and cutinase-N1 in octanoic acid/isooctane and vegetable oil. Moreover, new perspectives are open for the CBMs applicability 
in nonaqueous systems especially whenever the catalytic partner is less efficient. In the particular case of cutinase fused with CBM N1 production and application as a cellulose ester synthase will be an interesting strategy to pursuit and to optimize for textiles with biomedical applications.

Acknowledgments This work was co-funded by the European Social Fund through the management authority POPH and FCT, Postdoctoral fellowship reference: SFRH/BPD/47555/2008. The authors also want to thank Doctor Raul Machado for his valuable help on FTIR spectral data treatment.

\section{References}

Aquino AJA, Tunega D, Haberhauer G, Gerzabek MH, Lischka H (2002) Solvent effects on hydrogen bonds-A theoretical study. J Phys Chem A 106:1862-1871. doi:10.1021/ jp013677x

Araújo R, Silva C, O'Neill A, Micaelo N, Gübitz G, Soares CM, Casal M, Cavaco-Paulo A (2007) Tailoring the cutinase activity towards polyethylene terephthalate 6,6 fibers. J Biotechnol 128:849-857. doi:10.1016/j.jbiotec.2006. 12.028

Badenes SM, Lemos F, Cabral JMS (2010) Transesterification of oil mixtures catalyzed by microencapsulated cutinase in reversed micelles. Biotechnol Lett 32:399-403. doi:10.1007/ s10529-009-0172-5

Boraston AB, Nurizzo D, Notenboom V, Ducros V, Rose DR, Kilburn DG, Davies GJ (2002) Differential oligosaccharide recognition by evolutionarily-related $\beta-1,4$ and $\beta-1,3$ glucan-binding modules. J Mol Biol 319:1143-1156. doi: 10.1016/S0022-2836(02)00374-1

Bradford MM (1976) A rapid and sensitive method for the quantitation of microgram quantities of protein utilizing the principle of protein-dye binding. Anal Biochem 72: 248-254

Braun B, Dorgan JR (2009) Single-step method for the isolation and surface functionalization of cellulosic nanowhiskers. Biomacromolecules 10:334-341. doi:10.1021/bm8011117

Coutinho JB, Gilkes NR, Warren RAJ, Kilburn DG, Miller RC Jr (1992) The binding of Cellulomonas fimi endoglucanase C (CenC) to cellulose and Sephadex is mediated by the N-terminal repeats. Mol Microbiol 6:1243-1252. doi:10.1111/ j.1365-2958.1992.tb01563.x

Coutinho JB, Gilkes NR, Kilburn DG, Warren RAJ, Miller RC Jr (1993) The nature of the cellulose-binding domain effects the activities of a bacterial endoglucanase on different forms of cellulose. FEMS Microbiol Lett 113:211-217. doi: 10.1111/j.1574-6968.1993.tb06516.x

Creagh AL, Koska J, Johnson PE, Tomme P, Joshi MD, McIntosh LP, Kilburn DG, Haynes CA (1998) Stability and oligosaccharide binding of the N1 cellulose-binding domain of Cellulomonas fimi endoglucanase CenC. Biochemistry 37:3529-3537. doi:10.1021/bi971983o

de Barros DPC, Fonseca LP, Cabral JMS, Weiss CK, Landfester K (2009) Synthesis of alkyl esters by cutinase in miniemulsion and organic solvent media. Biotechnol J 4:674-683. doi:10.1002/biot.200800294

de Barros DPC, Fonseca LP, Cabral JMS, Aschenbrenner EM, Weiss CK, Landfester K (2010) Miniemulsion as efficient system for enzymatic synthesis of acid alkyl esters. Biotechnol Bioeng 106:507-515. doi:10.1002/bit.22726

de Barros DPC, Fernandes P, Cabral JMS, Fonseca LP (2011) Synthetic application and activity of cutinase in an aqueous, miniemulsion model system: hexyl octanoate synthesis. Catal Today 173:95-102. doi:10.1016/j.cattod.2011.05.039

Edgar KJ, Buchanan CM, Debenham JS, Rundquist PA, Seiler BD, Shelton MC, Tindall D (2001) Advances in cellulose ester performance and application. Prog Polym Sci 26:1605-1688. doi:10.1016/S0079-6700(01)00027-2

Ford ENJ, Mendon SK, Rawlins JW, Thames SF (2011) Spectroscopic analysis of cotton treated with neutralized maleinized soybean oil. J Am Oil Chem Soc 88:681-687. doi:10.1007/s11746-010-1712-9

Fouda MMG, Fahmy HM (2011) Multifunctional finish and cotton cellulose fabric. Carbohydr Polym 86:625-629. doi: 10.1016/j.carbpol.2011.04.086

Freire CSR, Silvestre AJD, Pascoal Neto C, Rocha RMA (2005) An efficient method for determination of the degree of substitution of cellulose esters of long chain aliphatic acids. Cellulose 12:449-458. doi:10.1007/s10570-005-2203-2

Freire CSR, Silvestre AJD, Pascoal Neto C, Belgacem MN, Gandini A (2006) Controlled heterogeneous modification of cellulose fibers with fatty acids: effect of reaction conditions on the extent of esterification and fiber properties. J Appl Polym Sci 100:1093-1102. doi:10.1002/app.23454

Gremos S, Kekos D, Kolisis F (2011a) Supercritical carbon dioxide biocatalysis as a novel and green methodology for the enzymatic acylation of fibrous cellulose in one step. Bioresour Technol. doi:10.1016/j.biortech.2011.09.056

Gremos S, Zarafeta D, Kekos D, Kolisis F (2011b) Direct enzymatic acylation of cellulose pretreated in BMIMCl ionic liquid. Bioresource Technol 102:1378-1382. doi: 10.1016/j.biortech.2010.09.021

Gübitz G, Cavaco-Paulo A (2008) Enzymes go big: surface hydrolysis and functionalisation of synthetic polymers. Trends Biotechnol 26:32-38. doi:10.1016/j.tibtech.2007.10.003

Hashem M, Elshakankery MH, Abd El-Aziz SM, Fouda MMG, Fahmy HM (2011) Improving easy care properties of cotton fabric via dual effect of ester and ionic crosslinking. Carbohydr Polym 86:1692-1698. doi:10.1016/j.carbpol. 2011.06.085

Koeller KM, Wong C-H (2001) Enzymes for chemical synthesis. Nature 409:232-240. doi:10.1038/35051706

Kormos J, Johnson PE, Brun E, Tomme P, McIntosh LP, Haynes CA, Kilburn DG (2000) Binding site analysis of cellulose binding domain CBDN1 from endoglucanase C of Cellulomonas fimi by site-directed mutagenesis. Biochemistry 39:8844-8852. doi:10.1021/bi000607s

Lizhi H, Toyoda K, Ihara I (2008) Dielectric properties of edible oils and fatty acids as a function of frequency, temperature, moisture and composition. J Food Eng 88:151-158. doi: 10.1016/j.jfoodeng.2007.12.035

Matamá T, Araújo R, Gübitz GM, Casal M, Cavaco-Paulo A (2010) Functionalization of cellulose acetate fibers with engineered cutinases. Biotechnol Prog J 26:636-643. doi: 10.1002/btpr.364 
Mittal A, Katahira R, Himmel ME, Johnson DK (2011) Effects of alkaline or liquid-ammonia treatment on crystalline cellulose: changes in crystalline structure and effects on enzymatic digestibility. Biotechnol Biofuels 4:41 (16p). doi:10.1186/1754-6834-4-41

Noureddini H, Teoh BC, Clements LD (1992) Viscosities of vegetable oils and fatty acids. J Am Oil Chem Soc 69:1189-1191. doi:10.1007/BF02637678

Peng H, Yang CQ, Wang S (2012) Nonformaldehyde durable press finishing of cotton fabrics using the combination of maleic acid and sodium hypophosphite. Carbohydr Polym 87:491-499. doi:10.1016/j.carbpol.2011.08.013

Prompers JJ, van Noorloos B, Mannesse MLM, Groenewegen A, Egmond MR, Verheij HM, Hilbers CW, Pepermans HAM (1999) NMR studies of Fusarium solani pisi cutinase in complex with phosphonate inhibitors. Biochemistry 38:5982-5994. doi:10.1021/bi990039k

Purdy RE, Kolattukudy PE (1975a) Hydrolysis of plant cuticle by plant pathogens. Purification, amino acid composition, and molecular weight of two isoenzymes of cutinase and a nonspecific esterase from Fusarium solani $f$. pisi. Biochemistry 14:2824-2831. doi:10.1021/bi00684a006

Purdy RE, Kolattukudy PE (1975b) Hydrolysis of plant cuticle by plant pathogens. Properties of cutinase I, cutinase II, and a nonspecific esterase isolated from Fusarium solani pisi. Biochemistry 14:2832-2840. doi:10.1021/bi00684a007

Rozzell JD (1999) Commercial scale biocatalysis: myths and realities. Bioorgan Med Chem 7:2253-2261. doi:10.1016/ S0968-0896(99)00159-5

Rustemeyer P (2004) History of CA and evolution of the markets. In: Rustemeyer P (ed) Macromolecular symposiaspecial issue: cellulose acetates: properties and applications. Wiley-VCH, Weinheim, pp 1-6
Schindler WD, Hauser PJ (2004) Chemical finishing of textiles. Woodhead Publishing Ltd, Cambridge

Sereti V, Stamatis H, Pappas C, Polissiou M, Kolisis FN (2001) Enzymatic acylation of hydroxypropyl cellulose in organic media and determination of ester formation by diffuse reflectance infrared Fourier transform (DRIFT) spectroscopy. Biotechnol Bioeng 72:495-500. doi:10.1002/10970290(20010220

Silva C, Azóia N, Martins M, Matamá T, Wu J, Cavaco-Paulo A (2012) Molecular recognition of esterase plays a major role on the removal of fatty soils during detergency. J Biotechnol 161:228-234. doi:10.1016/j.jbiotec.2012.06.019

Sitnitsky AE (2010) Model for solvent viscosity effect on enzymatic reactions. Chem Phys 369:37-42. doi:10.1016/ j.chemphys.2010.02.005

Steinmann HW (1998) Cellulose acetate and triacetate fibres. In: Lewin M, Pearce EM (eds) Handbook of fibre chemistryinternational fiber science and technology series/15. Marcel Dekker Inc, New York, pp 803-868

Tomme P, Creagh L, Kilburn DG, Haynes CA (1996) Interaction of polysaccharides with the N-terminal cellulosebinding domain of Cellulomonas fimi Cen C. 1. Binding specificity and calorimetric analysis. Biochemistry 35: 13885-13894. doi:10.1021/bi961185i

Uschanov P, Johansson LS, Maunu SL, Laine J (2011) Heterogeneous modification of various celluloses with fatty acids. Cellulose 18:393-404. doi:10.1007/s10570-0109478-7

Vaca-Garcia C, Thiebauda S, Borredona ME, Gozzelino G (1998) Cellulose esterification with fatty acids and acetic anhydride in lithium chloride/N, N-dimethylacetamide medium. J Am Oil Chem Soc 75:315-319. doi:10.1007/ s11746-998-0047-2 